WHAT ARE THE SYMPTOMS OF NEPHRITIS? BY ROBERT T. EDES.

JAMAICA PLAIN (BOSTON), MASS.

This question was asked in an editorial of the Journal of the American Medical Association of July 23,1898 , the writer in his comments seeming to intimate that the subject has been complicated rather than simplified by some oi the more modern observations, and that it is surrounded by needless mys. tery.

It is true that the diagnosis is not quite so simple as in the days when "albuminuria" covered almost the whole ground of renal pathology, while prognosis was brief and gloomy, and the clinical history prolix only, because of the great variety and severity of the symp. toms which might precede the fatal termination. That, however, was longer ago than the "few years" claimed by the editor. Forty years ago it was known that albumin was to be found in the urine in many cases which were not to be considered Bright's disease, and the number of conditions in which it may occur has been constantly added to until at last a "physiologic albuminuria" has been spoken of.

The significance of the presence of casts has undergone similar changes in estimated importance and for similar reasons, until the writers in the JourNal (Haines and Skinner, Jan. 29, 1898) claim that by their method of careful search casts may be found in samples of urine even from persons in perfect health. When these facts are brought into connection with another set of (as I believe, exceptional) observations, in which it is shown that the progress of a wellrecognized nephritis may be accompanied by neither of these important conditions-once considered almost, if not conolusively, pathognomonic-and when we find also that the person with the high arterial tension shown by the sphygmogram--which has been thought so highly characteristic that Mahomed used to speak of "Bright's disease without nephritis"-may live for years without developing any others, the bewildered student finds himself driven to the conclusion that the only persons who are free from the symptoms of Bright's disease are those who have the disease itself.

Now, whatever we may think, as a matter of taste or gratitude or scientific accuracy, of the propriety of naming diseases and symptom-groups after physicians, it seems clear that if we do so, the name should be applied to the conditions described by the writer, and not to something else more or less frequently associated with it, even if the subsequent author calls his the "true - - 's disease" and all others "spurious" or "pseudo.". Certainly Dr. Bright described well. recognized organic gross disease of the kidney, associated during life with the presence in the urine of albumin, detected by heat. He did not describe the hypertrophy of the heart as the disease, although he well knew that it was a frequent accompaniment, nor the high tension of the arteries, nor the casts which he had not seen, nor the traces of albumin which the reagents had not been invented to detect.

It seems that a portion of such obscurity and confusion as still surround the matter-which the editorial in question seems to have exaggerated-is due in part to confusion in nomenclature, in part to a tend. ency to overestimate the importance of rare exceptions, and to go from one extreme to the other, concluding that so soon as a symptom has been shown not to be pathognomonic it has no longer any value; and in part to another error which sometimes accompanies the development of greater accuracy in diagnosis and the recognition of earlier stages of diseases or perhaps even of a tendency thereto. I mean the mistake of attributing the clinical history and prognosis based upon the study of well-developed and advanced exam. ples to cases which have been recognized by more refined methods at an earlier stage-so early, in fact, that it may often be doubtful whether they have gone far beyond the bounds of normal activity or structure, Such recognition is of the highest value for prophy. laxis and therapeutics, but should be utilized with the utmost caution in prognosis, both for the sake of the patient's peace of mind and the physician's reputation; and this caution is never more necessary than in connection with the very class of diseases under consideration.

The following chain of reasoning-although I admit that it can not be found laid down in the books in exactly this form-does not greatly misrepresent the usual state of feeling among the profession not so many years ago, and not yet wholly extinct among the laity. A single observation of albumin in the urine meant albuminuria; albuminuria meant disease of the kid. neys; disease of the kidneys meant, in the great majority of cases, chronic Bright's disease; Bright's disease meant steady progress toward a not remote fatal termination, which might be interrupted at any time by various accidents which would still more accelerate it. Some of the links of this chain are weaker than others, but all of them have, of late years, been subjected to searching examination, and they may be taken up in order.

1. As to transient, physiologic or cylic albuminuria: Albumin in small quantity has been found either constantly or at frequent short intervals in the urine of many persons supposedly healthy or more frequently among those quite young who are not actually sick but are a little below par in general condition. When the intervals are more or less regular, usually coinciding with the periods of sleeping and waking, or more properly of lying down and getting up, it is called cyclic. In some exceptional cases a condition of constant albuminuria may last over months or years without manifest impairment of the general health.

In the majority of cases transient albuminuria is provoked by exposure of some kind, frequently such as tends to raise the arterial tension and thus bring more pressure to bear on the kidneys. Cold bathing is the typic example. Other conditions, however, figure prominently among the statistics of those who have found large proportions of albuminurics among healthy persons. Such are, for instance, excessive exercise, and vaccination, and the expectation of examination. What the local conditions are which give rise to transitory albuminuria it is difficult to say, as such cases are not likely to be the subject of postmortem exam. ination, but it is not going far to surmise that they involve some real, if slight and transient and easily reparable, change in the epithelium of the glomeruli. But a single observation showing albumin should not be considered of great diagnostic value, unless the quantity is large or there are other symptoms confirm. atory of the suspicions attaching to its presence, or unless repeated examinations show that it is more than temporary.

An exceedingly important point in regard both to this question and the next one, is that of the test used. 
TABLE I.-ALBUMINURIA AMONG PERSONS SUPPOSEDLY HEALTHY.

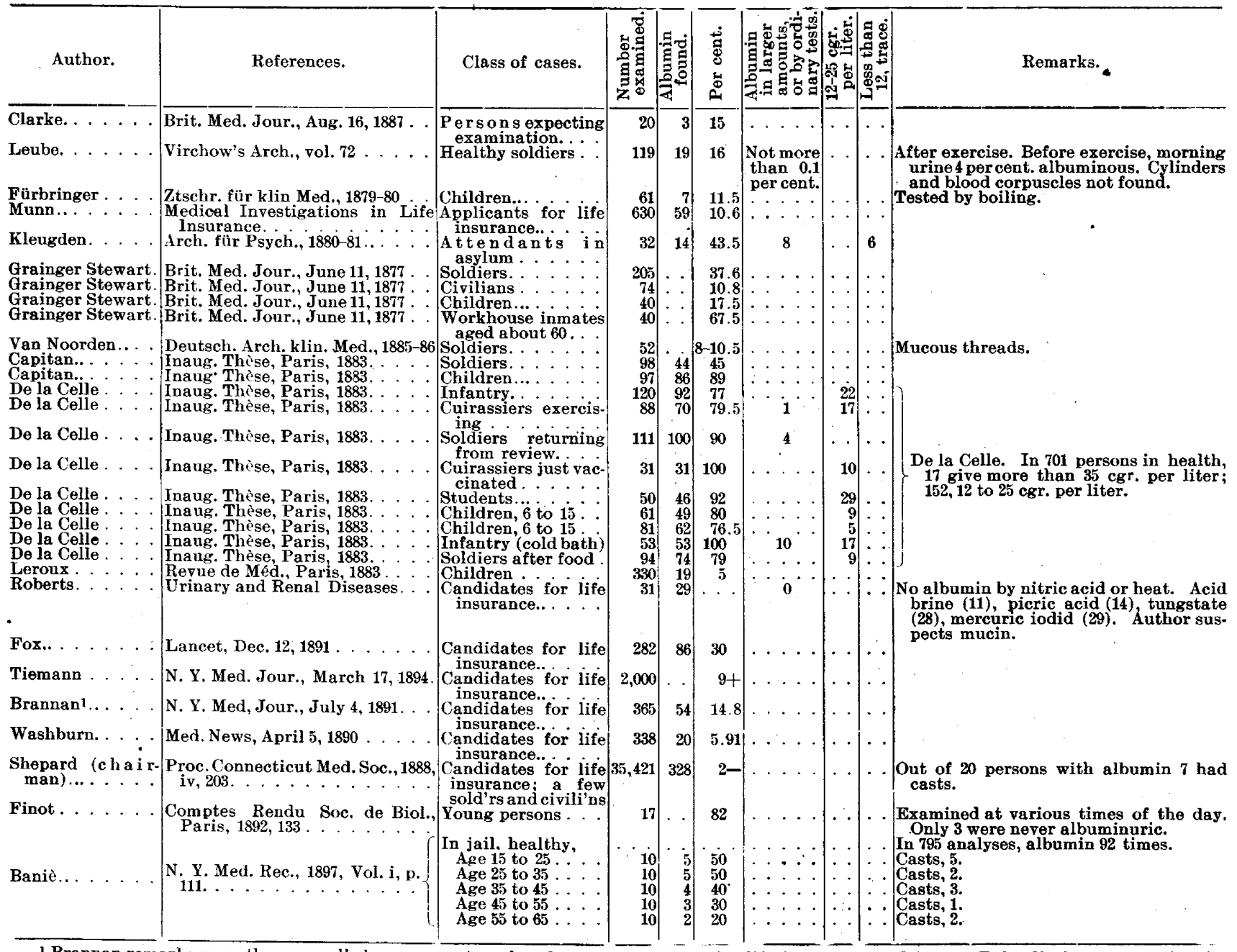

1 Brannan remarks upon the unusually large percentage found among candidates for life insurance, and quotes Rabagliati as accounting for this condition by saying that the well-to-do have more renal disease, because they eat and drink too much: This apparently does not apply to Shepard's figures.

As more delicate reagents have been employed, the proportion of cases in which albumin-or what is claimed as such-has been found increases, until with "Tanret" (iodohydrargyrate of potassium) it is said to occur in the majority of cases of healthy persons; rising to 0 per cent. in "soldiers returning from a review," and 100 among " cuirassiers just vaccinated" and "infantry after a cold bath." (De la Celle. See table.)

It is obvious that such a test as this is worse than useless, for it can give no useful information to the physician, while if results based upon it be communicated to the patient, it will implant in his mind an apprehension which no subsequent explanations can fully remove. There is no clinical value in a test which draws no line, not even an obscure and uncertain one, between danger and safety. The same remark will apply in less degree to some others, which shade in delicacy from the "Tanret" to the ordinary heat and nitric acid tests-not the "heat with nitric acid" test, which should never be used.

Probably these last mark most clearly and conveniently the point at which the line can best be drawn between the presence of albuminuria and "no;" i. e., a negligible amount of, albumin; and the physician who adheres to these, carefully used, will make less trouble for himself and his patient than with any other. He may, however, for convenience and to make sure,

sometimes find the acid brine or picric acid useful, and it is within the bounds of possibility that his attention might be called by even more delicate ones, in some exceptional cases, to a renal trouble that might otherwise be overlooked. Any errors of omission of this kind, however, would be as nothing beside those which he would make upon the other side if he adhered to any very excessively delicate test as a criterion of well-developed renal disease. If from 75 to 100 per cent. of healthy persons are known to have albumin in the urine, there is no use in searching for it, for experience tells us that only a much smaller proportion than this are the probable subjects of future renal disease, and neither its presence nor its absence can tell us which are the ones.

Some years ago I collected from various sources a number of tables showing the frequency of the occurrence of albumin, which are reproduced here with some subsequent additions. Among the most noticeable are those of a committee of the Connecticut Medical Society, of which Dr. Shepard of Hartford was chairman, which will be seen to differ very widely from many collected from nearly the same class of persons, which they might be supposed to approximate most nearly. Dr. Shepard says explicitly that he has taken no notice of cases where the albumin was not shown by the heat test. This paper is to be found in the Proceedings of the Connecticut Medical 
TABLE II,-ALBUMINURIA OF ADOLESCENTS. CYCLIC AND ACCIDENTAL ALBUMINURIA.

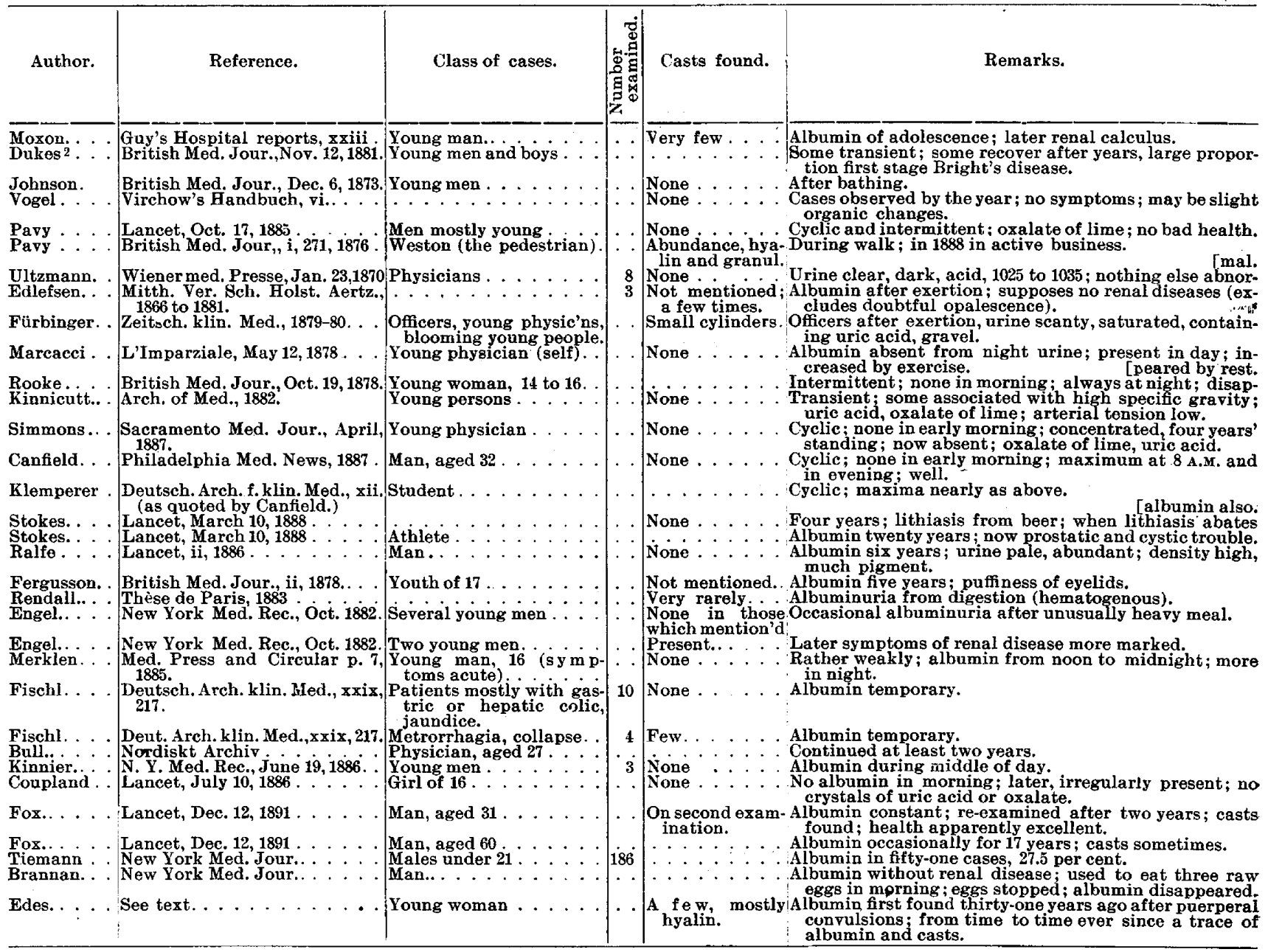

In a later article (Lancet, 1891, Vol. ii, pp. 1327-1382), Dukes remarks that these cases are much influenced by posture. Albuminuria occurs after standing. Also, these persons liable to faint on standing.

Society, N. S., Vol. iv, p. 203, Hartford, 1888, concealed under the highly descriptive title, "Matters of Professional Interest." This covers many thousand cases.

2. The more or less persistent presence of albumin is always of importance enough to call for a minute and careful search for other symptoms, but if these are not found in such a way as to decide the question, there has been a good deal of difference of opinion as to how seriously this one standing alone should be taken. This point is especially to be emphasized in reference to life insurance, that is as to the remoter prognosis.

Most authorities who have had the opportunity to study the subject from that point of view are quite clear that albuminuria constitutes a decided objection to a risk, although their own statistics, as well as the general experience, proves that there are many albuminurics, by the ordinary tests-that is, tests about as delicate as heat-who are in no immediate danger of chronic nephritis of sufficient intensity to give rise to any other symptoms for many years. In the face of the facts that in the vast majority of cases and under normal circumstances, no albumin whatever detectable by heat escapes by the urine, and that when it does so, some slight departure from normality may usually be found, and that when persistent there is in nearly all cases a deterioration of the general health (Munn, Dukes, Brannan), it is safe to say that albuminuria always means some trouble with the kidneys. Whether in all cases it has a right to the dignity of nephritis, is largely a matter of nomenclature.

We are originally furnished with perhaps twice as much renal tissue as is sufficient to take care of the excreta which normally pass in this direction. There is no disturbance of the balance of health until the secreting power is reduced, either by loss of substance or loss of function, or unless on some special occasion the demands upon it are considerably increased. Thus it is perfectly possible that. there may be some portion of the structure sufficiently damaged to let through a small portion of albumin without affecting the rest of the kidney, just as there may be, for instance, a few specially irritable regions. in the nasal passages or in the colon which secrete more than their normul amount of mucus without. impairing the functions of the remainder.

The observations of Munn (Medical Investigation in Life Insurance) showed that among the albuminuric candidates for life insurance the percentage of mortality was considerably above the normal, and that they all exhibited, after a lapse of time, a falling off in complexion and general appearance. Clement Dukes (Brit. Med. Jour., Nov. 12, 1881, and Lancet, Dec. 12, 1891), who has for years given attention to the albuminuria of adolescence, is far from regarding. it with indifference and has on at least one occasion. 
TABLE III.-ALBUMINURIA AMONG THE SICK.

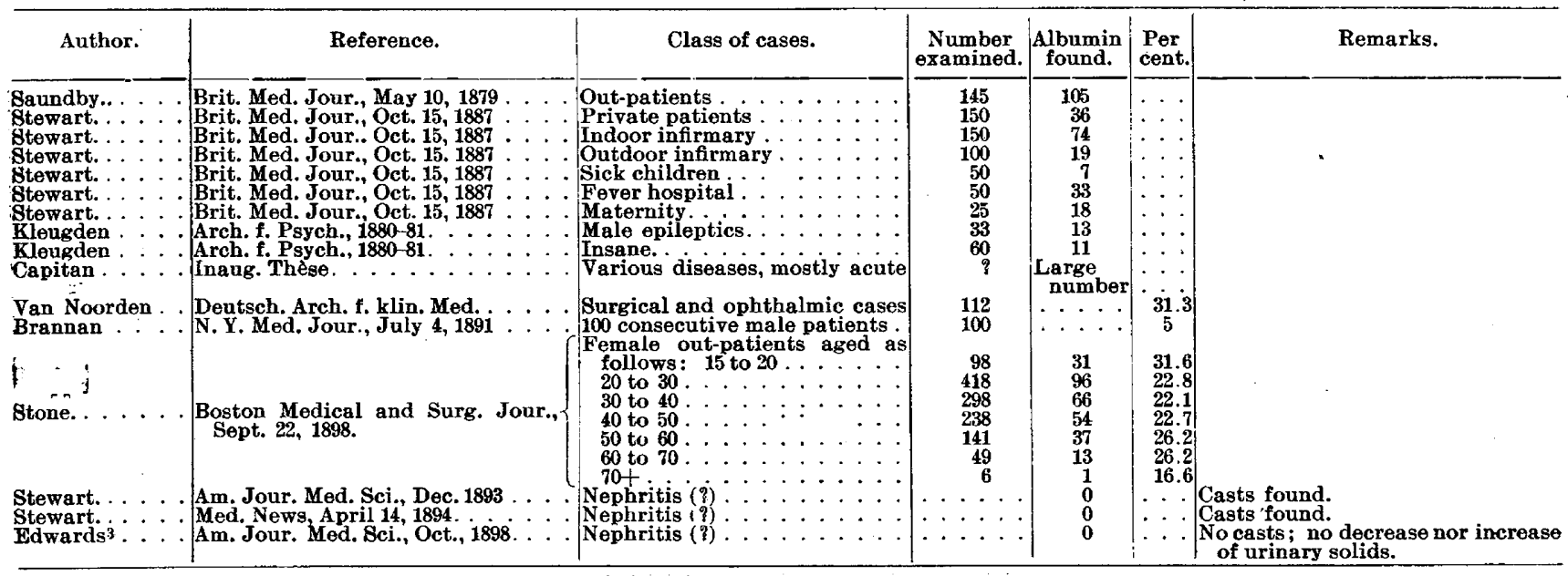

3 Refers to many authors who speak of the absence of albumin.

TABLE IV.-OPINIONS.

\begin{tabular}{|c|c|c|}
\hline Author. & Reference. & Remarks. \\
\hline $\begin{array}{l}\text { Gull } \ldots \ldots \\
\text { Johnson. } \ldots \ldots \\
\text { Deissier Haviand Hall. } \\
\text { Pye-Smith. . . . . . . . . . . }\end{array}$ & 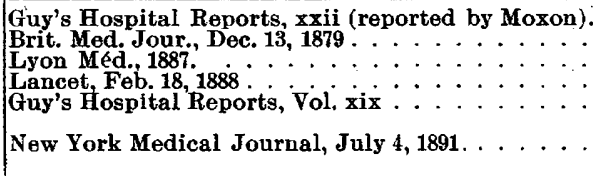 & $\begin{array}{l}\text { Albuminuria as common as spermatorrhea. } \\
\text { Lattent albuminuria means serious trouble } \\
\text { Subjects of cyclic albuminuria; probably all destined to goutiness. } \\
\text { Albuminurics should not be assured. } \\
\text { No person who has albuminous urine (by usual tests) can be con- } \\
\text { sidered eligible for life insurance } \\
\text { Derangement of function will sooner or later end in structural } \\
\text { change in kidney. }\end{array}$ \\
\hline
\end{tabular}

TARLE V.

\begin{tabular}{|c|c|c|c|c|c|c|c|c|}
\hline & Accidental. & Neurotic. & Irritative. & Asystolic. & $\begin{array}{c}\text { Chronic } \\
\text { parenchymatous } \\
\text { nephritis. }\end{array}$ & $\begin{array}{c}\text { Chronic } \\
\text { interstitial } \\
\text { nephritis. }\end{array}$ & $\begin{array}{l}\text { Subacute } \\
\text { nephritis. }\end{array}$ & $\begin{array}{l}\text { Cerebral } \\
\text { disease. }\end{array}$ \\
\hline Daily quantity of & Normal... . . & Increased.. . . & Diminished.. . . & Diminished.. . & Diminished.. . & Increased... . & Diminished... & Increased. \\
\hline $\begin{array}{l}\text { urine. } \\
\text { Specific gravity.. }\end{array}$ & Normal.. . . & Diminished.. & Increased... . . & Increased... . & Normal or in- & Diminished... & Increased or & Diminished. \\
\hline Albumin ... & $\begin{array}{l}\text { Varies in different } \\
\text { cases: only occa- } \\
\text { sionaly present, } \\
\text { perhaps. }\end{array}$ & Small amount & Small amount. . . & Varies. . & Much ..... & $\begin{array}{c}\text { Mod'rate, none } \\
\text { sometimes. }\end{array}$ & Moderate... & Small amount. \\
\hline Casts. . . . & $\begin{array}{l}\text { None or a very few } \\
\text { hyaline. }\end{array}$ & $\begin{array}{l}\text { None or a very } \\
\text { hyaline. }\end{array}$ & Few ........ & 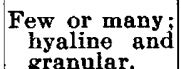 & $\underset{\text { kinds. }}{\text { any }}$ of all & $\mid \begin{array}{c}\text { Hyaline, e pi- } \\
\text { thel., granul'r }\end{array}$ & $\begin{array}{c}\text { Hyaline, epi- } \\
\text { thelial, gran. }\end{array}$ & Very few. \\
\hline Other sediment.. & Not important. . & Not import'nt. & $\begin{array}{l}\text { Uric acid, oxal. of } \\
\text { lime, ep. stained } \\
\text { with bile pigment } \\
\text { blood? }\end{array}$ & Urates .... & $\begin{array}{l}\text { Urates, epithe- } \\
\text { lium. }\end{array}$ & $\mid \begin{array}{c}\text { Uric acid? or } \\
\text { not important }\end{array}$ & $\begin{array}{c}\text { Epithe li u m, } \\
\text { urinary salts. }\end{array}$ & Not import'nt. \\
\hline Arterial tension & Normal...... & High ... & Normal or high. . & Diminished... . & Diminished.. . . & Increased.. . . & N ot much & High. \\
\hline Dropsy. . & None.......... & None. . & None: . & Lower limbs. & General . . . & Face, feet and & Slight..... : & None or very \\
\hline Eye ground. & Normal..... & Normal.. . & Normal... . & $\begin{array}{c}\text { Norma l or } \\
\text { hemorrhages. }\end{array}$ & $\mid \begin{array}{l}\text { Album, retinitis, } \\
\text { but less comm'n } \\
\text { than in next. }\end{array}$ & $\begin{array}{c}\text { Al bumi nur i c } \\
\text { retinitis,hem- } \\
\text { orrhages. }\end{array}$ & $\begin{array}{c}\text { Sometimes le- } \\
\text { sions, which } \\
\text { disappear. }\end{array}$ & Optic neuritis. \\
\hline
\end{tabular}

recognized in a college student, applying to him for dition of chronic nephritis. (Trans. Path. Soc. Lonmore advanced renal disease, one of his former albu- don, 1888-89, xi, 144.)

minuric boys. He says: "The cases of early albuminuria, so common in the young, constitute the early stage of what may eventually become developed into that chronic disorganization of the kidneys termed Bright's disease."

One of the most striking illustrations of the fact, that while albuminuria may be an exceedingly chronic symptom, it is not to be considered as without significance may be found in the history given by Dicken. son of an old family in which this symptom has been known to exist for at least four generations, while the family portraits seemed to him to give strong grounds for the suspicion that it extended back to a time when it was not sought for in the urine, but revealed itself by the complexion and general appearance to the experienoed eye of later physicians. Most of the persons affected died at a comparatively early age, and in one case the kidney examined and reported in con3. The distinction between acute nephritis and the forms of obronic renal degeneration more distinctively known as Bright's disease without any prefix, is too obvious not to have been at once recognized. The relationship between them was also well understood, so that although it was known that the acute might give rise to the chronic form it was by no means necessarily so, any more than it was'usual for pneumonia, for instance, to cause consumption, although such a thing might, under specially unfavorable circumstances, occur. But there seem to be cases between the two where the duration is distinctly too long and the intensity of the symptoms too slight to be considered acute, and on the other hand, do not deserve the inevitably fatal prognosis supposed to be connected with the diagnosis of Bright's. When a case of this kind recovers-either absolutely or relan- tively-it may be claimed on the one hand by the nection with Dickenson's paper was clearly in a con. therapeutic optimist as a "cure of Bright's disease," 
or may be, on the other, belittled by the skeptic as only "an acute case which was rather slow in getting well."

4. The knowledge of the extreme chronicity, as well as the insidious origin, of well-marked Bright's disease could only be acquired by the lapse of time, and many instances of so-called mistakes are due to this fact rather than to any error in diagnosis, properly speaking. A very interesting case is reported by Francis Hawkins (Trans. Clinical Society of London, 1892-3, xxvi, 216), of a medical man who had consulted Dr. Bright himself, and had been told by him that he had renal disease, and that death was inevitable within two or three years. He gave up his London practice, but died forty-three years later of cerebral hemorrhage. Stories of this character are apt to be told of many distinguished physicians, who see in their consulting practice a large proportion of cases that are difficult and obscure. They naturally contribute greatly to the comfort and hilarity of the laity. In the present one Dr. Bright may have been perfectly correct in his diagnosis and failed so sig. nally in his prognosis, because he was necessarily unaware of possibilities now familiar to all. The time that has elapsed since the practice of searching for urinary symptoms in cases-other than those where it is absolutely forced upon us-has become a common one, has taught us many things that he could not have known. Such cases show what we are finding out more and more in regard to many diseases, that an experience based on the hospital and deadhouse, which represent almost entirely the last stages-of chronic diseases, is not trustworthy as the sole guide in general practice.

A young woman had post-puerperal convulsions in September, 1867. Soon after and for a year later albumin was found in the urine. She was confined again in 1870 and in 1871, the children being sickly. Subsequent examinations of which $I$ have notes are as follows, and I have a strong impression that there were others of the same charaoter:

November, 1874. Albumin and casts, medium-sized, granular and one or two small hyaline. April, 1878. Considerable albumin ; small hyaline casts. September, 1887. Large trace of albumin; one cast. September, 1898. S. G., 1016; perceptible opalescence on boiling; slight cloudiness with picric acid; no perceptible line on underlying with nitric acid; several small hyaline casts. In 1887 she called to see me, and again in 1898, and is in fair health.

It certainly appears more probable in a case of this kind that some small local lesion has remained the same without extension to surrounding tissues, than that any general deterioration either of blood, of arteries, or of renal structures has withstood the shocks of subsequent pregnancies and the wear of thirty years without impairment of the general health.

On the other side of the albumin question, i.e., with reference to those cases of decided nephritis which have been for many years known to exist, where albumin is temporarily or even for long periods absent from the urine, they only emphasize the importance of inquiring in regard to all the symptoms in every case. Equal or superior in importance to albuminuria, comes the presence of casts, and then the quantity of urine and its solid constituents, condition of the heart and arteries, edema, nausea and anemia.

Several elaborate articles, based on a careful study, not only of the more obvious symptoms, but of the chemic constituents of the urine for twenty-four hours, have recently appeared by stewart ( $A m$. Jour. Med. Sci., December, 1893; Med. News, April 14, 1894) and Edwards (Amer. Jour. Med. Sci., October, 1898). The first named of these authors seeks to establish a special form of nephritis on the basis of absence of albuminuria. It seems very much like the "renal inadequacy" of Sir Andrew Clarke. In all of his (Stewart's) cases casts were found, but he seems to lay special stress in his diagnosis on the deficiency of both water and solid constituents in the twenty-four hours' urine. Of this it may be remarked that he has set his normal standard very high ( $35 \mathrm{gm}$. of urea) and, what is of perhaps more importance, there is little reason to suppose that such soluble and highly diu. retic substances as urea and chlorid of sodium fail to appear in the urine in sufficient quantity on account of any structural difficulty in passing them through. A comparison of cases of renal atrophy from hydronephrosis or renal calculus shows how small a rem. nant of secreting structure is sufficient to filter through large quantities of water, presumably carrying with it such salts as are very easily soluble therein. This condition of things points much more strongly to a deficient metabolism, which is a pathologic condition, but has no necessary relation to the kidneys in par. ticular, except from the fact that its products happen to come through those organs. It may indicate to the shrewd observer one of the directions in which danger may be anticipated, but it is not nephritis.

If, in such a cses as is reported by Edwards, nephritis is suspected when there are "no suggestive cardio-vascular findings, no albumin, no casts, no decrease in total solids, specific gravity or quantity," no edema mentioned, and this possible diagnosis is confirmed by the autopsy, we can only congratulate the physicians on their acuteness and feel that when a diseased organ presents absolutely no symptoms of abnormality in its products; and no evidence-except so very indefinite a one as nausea-of impaired function, nobody but a clairvoyant can be blamed for over. looking it. The "prealbuminuric stage of Bright's disease" of Mahomed and some others should be described rather as "a condition of the system, and in particular of the arteries, of which nephritis is one among several possible results."

The significance of a very small number of casts can not be quite so distinctly defined as that of a quantity of albumin determined by some standard test, because so much depends upon the skill, the luck, and especially the patience of the observer. If the painstaking method of Haines and Skinner $(l . c$.$) is$ followed, we can be reasonably sure that no casts have escaped us. It is possible that after this method has been in use for some time we may find that they are as common as excessively small quantities of albumin, in which case the symptom must cease to have any great value, unless the chief weight is laid upon their character rather than upon their mere presence. If, however, we adopt a less rigid and more convenient standard, that is, the examination with a low power of several drops of sediment from urine that has stood for a number of hours without decomposing, or obtained from the centrifugation of a considerable quantity, we stand on about the same level of accuracy with the heat test for albumin. Most statistics are not very trustworthy as to determining the importance of the finding of casts under these conditions, as there is no guarantee for even the degree of thor- 
oughness just described, but there is no doubt that casts are often found in small numbers when they do not greatly add to the gravity of the evidence afforded by small quantities of albumin. So that now opinion is changing in regard to them, somewhat as it has already done in regard to albumin, and there is danger of their signicance being overlooked or underestimated.

Two important limitations should be made. The casts, or so-called casts, of irregular outline and longitudinal striation, often tapering off into a tail at one end, and named, probably correctly, "mucous," are of no consequence whatever, or, at the most, if numerous, are significent only of a certain amount of superficial irritation of the kidneys. They may, however, occasionally deceive an inexperienced observer. True casts may be divided into two chief classes: the small and medium hyaline, which are probably formed in the caliber of tubes which retain their epithelium; and the larger sized ones which contain, or are chiefly composed of, epithelium more or less degenerated; and also more homogeneous ones which are apparently formed in tubes from which the epithelium has been shed. The second class can often be found at the autopsy in situ in kidney undergoing various forms of degeneration. They signify parenchymatous nephritis and by their number and character, give important information as to the extent and progress of the lesion. They are naturally of much more serious import than the small hyaline ones carrying now and then a cell. The large casts formed by solid masses of degenerated cells molded in a tube previously denuded of its epithelium or of which the lining forms the outer layer of the cast itself, and those solid ones with a sharp outline, frequently bearing the marks of a more or less complete resinous fructure, are of the most unfavorable significance, but are not often met with until the question of diagnosis has long ceased to be the most interesting one.

Shattuck (Boston Med. and Surg. Jour., 1894, cxxx, 613) has had many examinations made for the purpose of determining the frequency of casts, especially in persons of advancing years, and finds them more common as the patients are older, and not to be closely connected with other symptoms of renal disease, nor of special unfavorable import in such persons. This observation, howwever, is far from proving them of no significance, but shows simply the fact that there is always a reserve of renal structure and that if its destruction goes on slowly it may be years before that reserve is exhausted. The renal atrophy may be merely keeping pace with a diminishing call for activity of function dependent upon a less active metamorphosis of tissue. It corresponds to the postmortem observation of a narrow zone of atrophy just underneath the capsule, dependent upon a chronic interstitial nephritis, which has not destroyed any large proportion of secreting structure.

Mitchell (New York Medical Times, xxiii, No.7, p. 201, July, 1895) has examined his records of persons whose condition was known for seven years after albumin and casts have been found. He concludes: "Where casts are found, together with albumin"- he used heat test-c"the mortality is nearly three times as great ( 30 per cent.) as in the non-albuminous cases (11 per cent.), and more than twice as great as in those who have albumin without casts (14 per cent.)."

A part of the difference between the non-albuminuric and the simply albuminuric orses was thought by Mitchell to be attributable to "accidental albumin uria," but in the presence of a microscopic examinaation that can hardly be of much importance.

It is only in the early stages and in regard to the preliminary questions that the albumin and casts are to be consided separately. In the permanent presence of albumin it is not safe, so far as most observations go, to assume the absence of casts because they are not mentioned, and on the other hand it is certainly not usual to find casts without the presence of a trace of albumin.

It is safe to say that the presence of albumin by the ordinary tests is proof of some disorder in the glomeruli, either as to blood pressure or soundness of epithelium or both, and that casts, according to their structure, either exudative or degenerative, prove dis order of the epithelium lining of the tubes, whether merely irritative or amounting to total disorganization. How extensive or how slowly progressive these changes may be is another step in the diagnosis, but they are never strictly physiologic, except in the sense that normal and natural reactions to abnormal conditions may be called so.

A condition which very frequently accompanies one form of nephritis - so frequently, indeed, that it has placed its stamp thereon and almost withdrawn it from the category of simple local inflammations, making of it a constitutional disease-is the high arterial tension. So early is it that Mahomed used to speak, not only of a "prealbuminuric stage of Bright's disease," but of "Bright's disease without nephritis." But this also fails of pathognomonic significance in the absence of the two symptoms just under discussion.

The sphygmograms of many cases of neurasthenia closely resemble those considered as characteristic or intestinal nephritis, that is, of an arterial pressure continuing high through too long a part of the diastolic interval, and indicating too great resistance to the passage of the blood in the distal portion of the circulation. The absolute pressure in the neurasthenic cases is probably less in the average than in the true arteriosclerotics, but the opposition to the escape of the blood through the arterioles is such in proportion to the force with which it is thrown into them, that a tracing is produced, similar in form, though often lacking in amplitude. This condition, as I have observed in many cases, is in no way a precursor of chronic nephritis. (Boston Med. and Surg. Journal, May 19, 1881 and July 18, 1895.)

Many years ago I took some tracings from members of a medical club, among which were two which would, I think, by any one who had given attention to the subject, have been considered highly characteristic of chronic interstitial nephritie. One of these confréres died three years afterward, not of interstitial nephritis, but of interstitial hepatitis. The other, after practicing for many years longer, gave up finally on account of sciatica and the infirmities of age, and died at 85 , never having given any signs of nephritis.

On the other hand, although the usual conception of the nephritis and the high arterial tension as two, perhaps equally important, parts of a common morbid condition, is applicable to the great majority of cases, yet it is probable that in some the arterial and cardiac lesions are distinctly the result of a nephritis of purely local origin.

I recall the case of a boy with atrophy of the kid. neys, evidently dependent upon obstruction in the 
urinary passages, as shown by dilatation of the ureters and trabeculation of the bladder, who had a heart pronounced by competent authority to be hypertrophied, a condition for which there was nothing to account except increased arterial tension, which had not, however, been observed during life. There had been peculiarities of micturition, although after death there was no obstruction to the passage of an instrument through the ureters or urethra in either direction.

It is my belief that the origin of many cases of interstitial nephritis in young persons, where no other sufficient cause is to be found, might be successfully sought for in some difficulty of micturition, often functional, dependent upon irregular and incoordinated muscular and nervous action. (See Bechterew. Neurologisches Centralblatt, Sept. 15, 1898.) This may have been so slight as to escape serious notice but yet sufficient to set up a back pressure in the ureters and kidneys which would lead to hydronephrosis and atrophy. (Medical News, Aug. 10, 1899.)

The fact, now well known, that a man who has albumin in his urine is not thereby doomed to an early death, and the later statistics of Shattuck and Mitchell confirmed by many isolated observations, showing a similar significance as attached to casts, are likely to lead to false conclusions if they are taken to prove that these positive and distinct conditions are without important meaning. A marked change in either direction in the daily quantity of urine, as determined by actual measurement, is of great value as a symptom, but an excess or espeoially a diminution in comparison with the average usually stated as normal, should not be too hastily referred to renal derangement. In fact, in the early and doubtful stages, to which this paper chiefly refers, the kidneys are fully able to take care of all the water, urea, and probably all the other soluble salts, brought to them in the blood.

Pollakiuria or frequency of micturition, especially at night, although it should call for a careful examination of the urine, may be entirely unconnected with any disease of the kidneys or even of the bladder, being often of purely neurotic origin.

The amount of urine is influenced by many circumstances beside the condition of the kidneys: the vascular tension, which, as we have seen, is not necessarily connected with nephritis, the activity of the skin and bowels, probably the dryness of the surrounding atmosphere, and in particular the habits of the patient as regards the quantity and diuretic quality of liquids taken. A considerable diminution in the daily amount of urea excreted does not signify that the kidneys are inadequate to cope with it, but that for some other reason the metamorphosis of nitrogenous tissue is diminished. A copious flow of pale urine of a specific gravity below the normal average will for months or years carry off all the urea formed.

How far this applies to other substances less abundant, less diuretic, and less well known; perhaps to some others formed only under pathologic conditions, is not so certain. The presence of autogenetic poisons as the cause of many symptoms in renal disease is one of the interesting questions yet to be answered by the physiologic chemist and clinician together. 'There are grounds for suspecting the uric acid group and some coloring matters, but the proof against them is not conclusive. The ordinary urates are not so bad as they look.

\section{PRECORDIAL AREA IN CHILDREN.}

Presented to the Section on Diseases of Children, at the Forty ninth Annual Meeting of the American Medical Association, held at Denver, Colo., June 7-10, 1898.

BY H. B. WHITNEY, M.D. DENVER. COLO.

At the Pan-American Congress in 1893 , I presented a paper on "The Normal Precordia in Infancy and Childhood," and this paper was afterward published in the Archives of Pediatrics. Subsequent observation has not changed the views expressed at that time, nor have I anything to add to them. I shall, there. fore, merely give you the briefest possible résumé of the original paper, my present purpose being to mark out the precordia in a few children of different ages, and invite criticism of the results obtained.

I have ventured to bring up this subject again because, in the first place, I regard the question of the normal precordial area as of the greatest practical interest and importance; and if my observations have been correct, it seems to me desirable that the facts should be universally accepted. In the percussion of the heart we are dealing with a measurably constant and unvarying quantity; our results ought to be proportionately reliable. I am aware of the great differences of opinion which have always prevailed in regard to the precordial area, and these have been so divergent as to produce in some the conviction that anything like unanimity of opinion is hopeless; that differences of method and skill will always make percussion of the heart a purely individual matter. I can not take this pessimistic view. To me there is nothing in physical diagnosis more definite and more certainly ascertainable than the normal area of precordial dulness. I am, therefore, hopeful that a practical comparison and discussion of methods may at least further an agreement among those who are here present.

Hitherto no text-book in pediatrics has done more than state in a general way that the precordia of in. fancy and childhood is enlarged. Weil emphasized the fact in 1879, but made no distinction as to age. Other writers since Weil have simply repeated his statements. I will give, in illustration, only a short paragraph from that latest and most admirable book on pediatrics, "Holt's Diseases of Infancy and Child. hood:" "The outline of the area of relative cardiac dulness, especially in small children [italics mine], is proportionately larger than in adults. . . . According to Sahli, the limits are as follows," and then limits are given, corresponding precisely to those originally found by Weil, and to those which I shall attempt to demonstrate at certain ages. This persistent reappearance in the text.books of the old and, according to my conviction, incorrect statements, is the second reason why I again call your attention to my former paper.

The gist of my own observations may in a word be stated as follows: 1. Up to the age of 5 years the precordial area is not perceptibly enlarged, but corresponds practically with that of the adult. This statement concerns mainly its right border, which in the adult is a perpendicular line corresponding very nearly with the left border of the sternum. 2. From the age of 8 years up to and considerably beyond the age of puberty, the normal precordia differs markedly from that which is found in earlier life. Its right border now extends a half inch or even more bevond the right sternal margin; while the upper border is 